Article

\title{
Computer Aided Design to Produce High-Detail Models through Low Cost Digital Fabrication for the Conservation of Aerospace Heritage
}

\author{
Jose Luis Saorín $^{1}{ }^{\mathbb{D}}$, Vicente Lopez-Chao ${ }^{1, * \mathbb{C}}$, Jorge de la Torre-Cantero ${ }^{1}$ \\ and Manuel Drago Díaz-Alemán ${ }^{2}$ \\ 1 Engineering Graphics Area, University of La Laguna, 38204 Tenerife, Spain; jlsaorin@ull.edu.es (J.L.S.); \\ jcantero@ull.edu.es (J.d.l.T.-C.) \\ 2 Department of Fine Arts, University of La Laguna, 38204 Tenerife, Spain; madradi@ull.edu.es \\ * Correspondence: vlopezch@ull.edu.es
}

Received: 7 May 2019; Accepted: 3 June 2019; Published: 6 June 2019

\begin{abstract}
Aerospace heritage requires tools that allow its transfer and conservation beyond photographs and texts. The complexity of these engineering projects can be collected through digital graphic representation. Nevertheless, physical scale models provide additional information of high value when they involve full detailed information, for which the model in engineering was normally one more product of the manufacturing process, which entails a high cost. However, the standardization of digital fabrication allows the manufacture of high-detail models at low cost. For this reason, in this paper a case study of the graphic reengineering and planning stages for digital fabrication of a full-scale high-detail model (HDM) of the spatial instrument of the European Space Agency, named the Solar Orbiter mission Polarimetric and Helioseismic Imager (SO/PHI), is presented. After the analysis of this experience, seven stages of planning and graphic reengineering are proposed through collaborative work for the low cost digital manufacture of HDMs.
\end{abstract}

Keywords: engineering graphics; digital manufacture; 3D printing; computer-aided design; Autodesk Fusion 360; aerospace heritage

\section{Introduction}

The Design and Digital Manufacturing Laboratory of the University of La Laguna (Fab Lab ULL) has worked in the digital fabrication of a full-scale high-detail model (HDM) of the spatial instrument of the European Space Agency, named the Solar Orbiter mission Polarimetric and Helioseismic Imager (SO/PHI) [1]. This sort of physical replica entails deep information, which is essential for the preservation and transfer of aerospace heritage since projects launched into space are normally designed in order to not return to Earth.

The manufacturing of the HDM of the SO/PHI instrument was carried out under an approach that combined digital manufacturing techniques (low cost $3 \mathrm{D}$ printers, a CNC milling machine, and a laser cutting machine) and the use of a 3D computer-aided collaborative modeling software. The aim of this paper is to provide stages in the graphic engineering procedure for the digital fabrication of challenging projects, which require high detail through the resolution of a case study: the manufacture of a full-scale HDM of the spatial instrument PHI for the Solar Orbiter mission of the European Space Agency.

Rapid prototyping has made it possible to print 3D physical prototypes from CAD files [2]. However, this process is not always fast (since the model is not a single piece, and the printing process is not instantaneous). This lack of immediacy is plausible in architecture environments, where reduced scale models are indispensable and geometric simplification processes are required since buildings cannot be uniformly scaled [3]. 
3D digital printing precision and other fabrication variabilities have been a focus of interest in the scientific literature, including studies that compare the difference between the CAD model and the physical model [4]. In addition, other issues have dealt with the use of different digital manufacturing techniques with materials such as concrete [5] or the study of numerical models to analyze the behavior of timber folded surface structures using semi-rigid multiple tab and slot joints [6].

Nevertheless, there are many other challenges [7] when we face manufacturing a full-scale HDM of an engineering project. Although details are easily achieved in digital modeling, physical models provide important additional information for the conservation of engineering heritage, such as SO/PHI. Therefore, this article proposes a procedure to recreate engineering projects without the need for geometric simplifications through the use of low-cost digital fabrication methods.

\subsection{Replicas for Aerospace Industrial Heritage}

Heritage conservation awareness has increased and therefore, engineering graphics literature has recognized more and more research in different areas of heritage, whether industrial [8], sculptural [9], fossil [10], or architectural [11]. The term industrial heritage has been related to remains of constructions or inventions. However, in certain areas of engineering that possibility does not come to be, as it is in the aerospace sector. Therefore, space engineering projects has become critical evidence of the development of humanity, and consequently they remain part of our heritage [12]. For this reason, some researchers have demanded the need to act in the cataloguing and storage of aerospace heritage, indicating that published data are insufficient since they simply state the launch date, the name of the satellite, and the orbit [13].

Graphic representation is one of the tools that can contain and relate more information. In this sense, there are investigations focused on the use of digital representation such as the use of photogrammetry for the generation of three-dimensional modeling [14], augmented reality to visualize the industrial heritage [15], the application of BIM techniques for the representation of architectural heritage with a high level of detail [16] and the use of simplified models in educational environments to promote cultural heritage [17], including the supply of NASA stl files [18].

Photogrammetry and BIM can make a digital 3D model, the first one is faster has lower precision than the second one. Once the 3D model is created, it can be viewed digitally (augmented reality) or physically (scale model). The first has the level of detail that has been granted in digital modeling, while physical models usually entails geometric simplifications of the engineering project due to manufacturing or financial limitations. However, physical models allow a person to approach them in their real environment, so they can manipulate and understand them through the sense of touch. Meanwhile, the digital environment uses zoom or rotation tools to approach the pieces or rotate them, which can generate a distorted view of reality.

Although the 3D modeling programs have increased their use in engineering environments for the visualization and evaluation of the designed elements [19], tangible models are still indispensable because the physical interaction with the model helps to understand it, evaluate it and detect design problems [20]. The additional information incorporated in the models has been a focus of analysis in historical research [21]. In addition, it allows a more direct and personal interaction and visualization by investors, clients, designers, and other professionals who may be involved in the project.

\subsection{Scale Models: Architecture vs. Engineering}

The model has been a vital tool for the design of architectural projects, since it was necessary to understand and visualize large-scale buildings in different stages in order to minimize and prevent problems that might arise. The feasibility of its elaboration was based on the use of straight geometries and orthogonal angles, which can reduce three dimensions to two dimensions, and the need to simplify details in order to address reducing scale models. 
However, engineering projects need to reproduce complex geometries with high detail, such as the engine of a car. For this reason, scale models in this area have normally corresponded to industrial objects, made with the same process, cost, and materials as the original one.

Likewise, scale models of small elements have traditionally been made enlarging scale (instead of full scale), which has not allowed to visualize them in the context of the project. Currently, this precision can be achieved with low cost 3D imaging, by reaching resolutions up to $20 \mu \mathrm{m}$ in PLA (polylactic acid by fused deposition modeling) and $0.01 \mu \mathrm{m}$ in photosensitive resin (by digital light processing-DLP). Therefore, they become a fundamental tool for the development of full scale HDMs.

In architecture and design, prototyping has been conceived as a design method to study and test how a new product is going to be used, and how it will look [19]. This concept has conceived utility in models beyond the final result, so that there are different categories for the objectives of each phase of the project design. These categories can be classified as follows [22]:

- Soft model: Modeled by hand and allow exploration, and evaluate the size, proportion, and shape of concepts and ideas.

- Hard model: Usually made of wood, plastic, metal, or dense foam. It is not technically functional, but it is presented as a replica very close to the final design.

- Presentation model: With every detail of composition, in which the components have been simplified to save time.

- Prototype: High quality and functionality produced to exhibit a design solution.

Nonetheless, technological progress has generated changes in the manufacturing process of scale models, from conventional model making to methods such as rapid prototyping. The first method involves creative approaches and is more efficient in economic terms, while the second is an automated process through a digital model of the project, and higher cost. Thus, standardization of the use of low-cost 3D printers allows complex geometries and a high level of detail to be created whether both model manufacturing methods are combined.

\subsection{Collaborative Working Environment in Engineering}

Collaborative work has been fundamental to solve engineering challenges. In this sense, cloud storage services, collaborative environments, and social networks offer advantages and limitations [23] that despite its usefulness to communicate, write, and present results, do not allow 3D modeling.

In recent decades, engineering software companies have focused on solving this difficulty by offering high-cost collaborative work platforms (Autodesk Vault, PTC PLM Cloud, or 3D Experience). In this context, Fusion 360 from Autodesk emerges, a collaborative 3D modeling environment that is free for educational and for start-ups generating less than $\$ 100,000 /$ year in total revenue or wholly non-commercial hobbyist users [24]. This software is easy to use, integrates several assisted design environments, and also has a smartphone application for viewing modeling, as well as offering a public web link to visualize the model in the browser [25].

In this article, the case study of the manufacture of a replica of the spatial instrument SO/PHI is provided. The incorporation of low-cost digital fabrication machines (below \$2500) is proposed to solve the traditional characteristics in the manufacture of scale models such as geometric simplification and the high economic cost of detailed prototypes [20,22]. In addition, this approach aims to generate a framework of procedures and techniques of engineering graphics for the conservation and transfer of industrial heritage.

\section{Materials and Methods}

\subsection{PHI Instrument and Solar Orbiter Mission}

The Solar Orbiter mission, developed by the European Space Agency (ESA) in collaboration with NASA, focuses on the study of the Sun and magnetic activity in the heliosphere and will be able to 
obtain unique information to help understand the operation of this star and even predict its behavior. One of its devices, the PHI instrument (composed of about 1500 pieces) is the largest and perhaps the most complex. It will provide high-resolution and full-disk measurements of the photospheric vector magnetic field and line-of-sight (LOS) velocity as well as the continuum intensity in the visible wavelength range.

Due to its complexity, this instrument has been developed by an international consortium involving Germany, Spain, and France among other countries. The coordination of the Spanish part is carried out by the Institute of Astrophysics of Andalusia (IAA-CSIC), the Institute of Astrophysics of the Canary Islands (IAC), the National Institute of Aerospace Technology (INTA), the University of Valencia, the University of Barcelona, and the Technical University of Madrid.

Fab Lab ULL has produced the two-dimensional graphic documentation and the full-scale high-detail model of the SO/PHI, in order to explain its morphology and disposition of subassemblies. This physical model allows the dissemination of the research carried out by the Spanish part and is intended to have the same level of detail as the original project.

\subsection{Case Study Procedure}

The project begins with the reception of the original digital model that contains all the information of almost 1500 pieces modeled in 3D in step format. From them, a process of graphic re-engineering is carried out to prepare the pieces for their manufacture. First, six teams prepare the plans for the manufacture of the model. Subsequently, two teams and two supervisors create the replica through additive techniques (3D printing in polylactic acid, and photosensitive resin) and subtractive techniques (CNC laser cutting and cutting in PVC and methacrylate).

The resolution of this problem, which enables the conservation and transmission of aerospace heritage, is presented as a case study to establish graphic engineering procedures that allow the creation of HDMs based on low-cost digital manufacturing.

\subsection{Materials}

\subsubsection{Collaborative CAD Software}

The process is conducted in Fab Lab ULL and Autodesk Fusion 360 is used. The choice of this parametric design tool lies in its viability to work collaboratively as it is developed in an online environment. It also offers a platform in the cloud of Autodesk for the management and visualization of 3D models called A360. This software is conceived for the manufacture of digital products, through 3D printing, CNC milling, or laser cutting.

This research relates the resolution of a HDM through collaborative work and with low cost digital fabrication machines. In this way, the process can be replicated by small companies that are dedicated to the field of modeling.

\subsubsection{Manufacture Means}

Three low-cost 3D printers are used in the project: Two for printing by fused deposition (PLA) and one for DLP digital light processing (photosensitive resin), a laser cutting machine, and a CNC milling machine. Table 1 shows the technical specifications of the 3D printers.

Table 1. Technical specifications of the 3D printers.

\begin{tabular}{ccccc}
\hline 3D Printer & Prize (€) & Printing Material & Resolution $(\boldsymbol{\mu m})$ & Print Volume $(\mathbf{m m})$ \\
\hline BQ witbox 2 & $<1400$ & PLA & up to 20 & $297 \times 210 \times 200$ \\
Wanhao duplicator 7 & $<750$ & ABS & up to 0.01 & $120.96 \times 68.5 \times 180$ \\
\hline
\end{tabular}




\subsubsection{Materials for the Manufacture of the SO/PHI HDM}

For the manufacture of the model, the following materials are used: PVC and methacrylate (for the largest bi-dimensional parts), PLA (polylactic acid—for the model elements that require greater complexity and detail), photosensitive resin (for those elements that require higher levels of precision), acrylic paint (applied with a spray gun to achieve a uniform and homogeneous result), aluminium rods, and steel sheets.

\section{Results}

\subsection{Re-Engineering of the Original 3D Model}

\subsubsection{Identification and Organization of Sub-Assemblies}

In a first phase, it is necessary to organize the project into smaller and more manageable parts. For this, the different subassemblies that make up the PHI instrument assembly are grouped and a workspace is created in A360 for the management of the files. This consists in the creation of a Fusion 360 project that is shared with all the Fab Lab ULL team members who worked on this digital model. Thus, each member has access to all the information from the first moment. Furthermore, each person has one or more sub-assemblies assigned.

The classification and labelling system of the 17 sub-assemblies that structure the SO/PHI is essential. For this, transparent plastic containers with labels and with the plans for their manufacture are prepared to store, in an orderly manner, all the pieces that were going to be printed of each subassembly (see Figure 1).

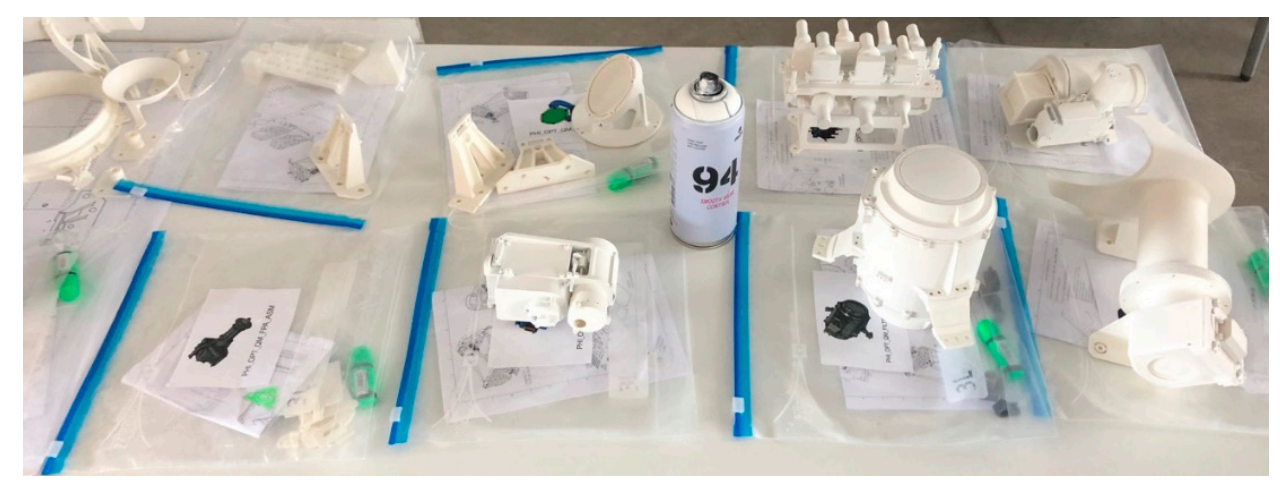

Figure 1. Classification and labelling of SO/PHI sub-assemblies.

\subsubsection{Analysis of the Digital Files}

The first problem consists in the management of the files and the organization of the subassemblies. Although the original model could have a certain organization by the different subassemblies, files in step format can lose part of the information when they are imported, so it is necessary to review and order their content.

File management begins with the detection of geometry problems. The fact that much of the digital model will be printed in 3D requires working with solid geometries, rather than surfaces. This factor is also important for the creation of plans since in Fusion 360 the elements modeled with surface geometries cannot be visualized in the 2D plans.

In the following pair of figures (Figure 2a,b) the received model (located on the left) and the model converted to solid are displayed. In the original file, solid geometries are perceived in the lower part of the subassembly, while in the rest, no cuts are generated because they are surface geometries. However, once the primitive geometry has been modified to solid geometry, the cut is visible throughout the sectioned part. 


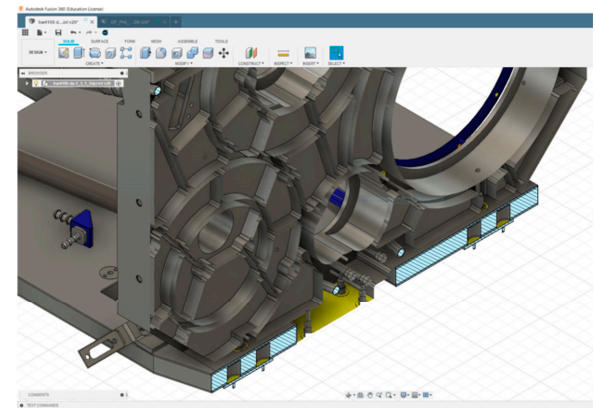

(a)

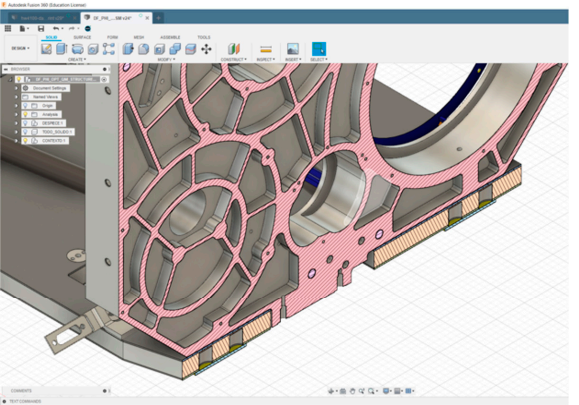

(b)

Figure 2. (a) Digital model with surface geometries. (b) Digital model with solid geometries.

\subsubsection{Digital Model Repair}

Once the detection and categorization of problems derived from the geometry is generated, it is required to correct the errors (overlaps, intersections...) and their subsequent transformation into solid geometry.

In the surface environment of Fusion 360, the stitch tool allows the surface to be sewn, and if it detects that the selection is a closed surface, it will convert it directly into a solid. If it were not a closed element, the interface highlights the perimeter lines of open surfaces in red (see Figure 3). In this case, the thicken tool can be applied to give thickness to the surface and convert it into a solid with the dimension that we have requested.

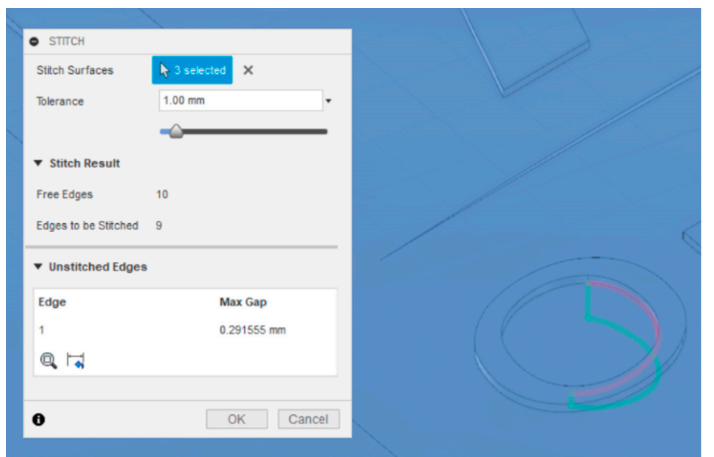

(a)

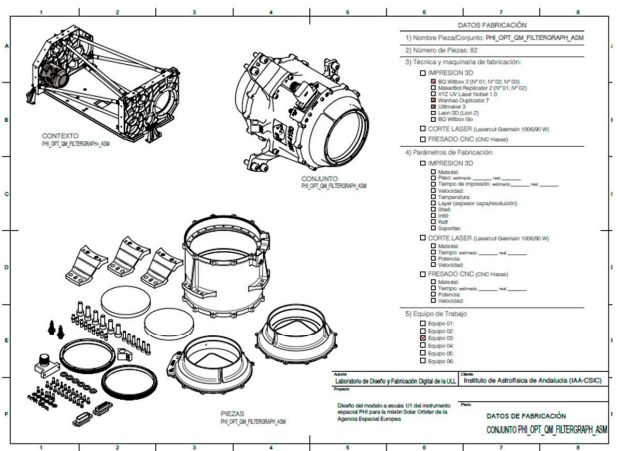

(b)

Figure 3. (a) Open surface detected through Stitch tool. (b) Subassembly 8 plan.

Once this process is completed for each subassembly, it is possible to start the creation of plans for manufacturing. In Figure $4 \mathrm{~b}$ the planes of the Subassembly 8 are shown. Once all the surfaces are transformed into solids, all the parts (pieces, screws, and nuts) that make up each subassembly of the complete model can be quantified (Table 2).

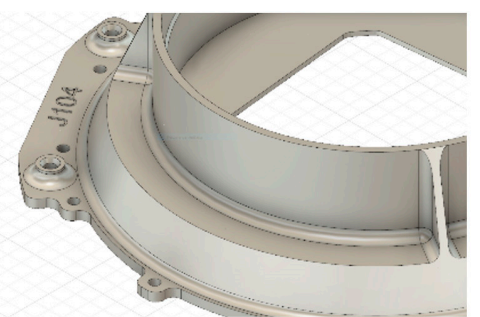

(a)

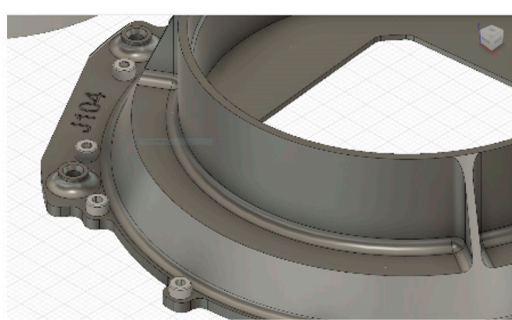

(b)

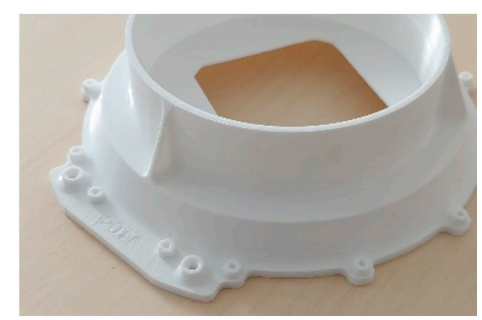

(c)

Figure 4. (a) Piece without screws in Fusion 360. (b) Piece with screws in Fusion 360. (c) Piece printed with screws. 
Table 2. Frequency analysis of pieces that integrate the SO/PHI subassemblies.

\begin{tabular}{lccl}
\hline & Pieces & $\begin{array}{c}\text { Screws and } \\
\text { Nuts }\end{array}$ & Total \\
\hline Subassembly 1 & 25 & 58 & \\
Subassembly 2 & 8 & 34 & \\
Subassembly 3 & 10 & 37 & \\
Subassembly 4 & 3 & 0 & \\
Subassembly 5 & 3 & 36 & \\
Subassembly 6 & 26 & 110 & \\
Subassembly 7 & 3 & 68 & \\
Subassembly 8 & 14 & 52 & \\
Subassembly 9 & 11 & 42 & \\
Subassembly 10 & 28 & 7 & \\
Subassembly 11 & 2 & 190 & \\
Subassembly 12 & 41 & 0 & \\
Subassembly 13 & 8 & 50 & \\
Subassembly 14 & 12 & 107 & \\
Subassembly 15 & 49 & 197 & \\
Subassembly 16 & 51 & 1156 & \\
Subassembly 17 & 19 & 313 &
\end{tabular}

\subsubsection{Digital Model Restructuration to Optimize Their Manufacturing}

It is essential to group geometries to optimize printing times. In particular, the screws and nuts (and other small elements) associated with each subassembly can be grouped in such a way that they can be printed in a single process. Screws and nuts can be embedded in subassembly parts since their mechanical operation is not necessary (i.e., Figure 4).

To shed light on the decrease in printing parts that this process entails, Table 3 presents data on the reduction of parts for Subassembly 8. In this case, the percentage of parts removal is 83 . This situation is analyzed for each of the assembly subassemblies.

Table 3. Simplification of pieces of Subassembly 8.

\begin{tabular}{cc}
\hline Subassembly 8 & Pieces \\
\hline Original & 82 \\
Prepared for printing & 14 \\
\hline
\end{tabular}

In Figure 5, the geometric modeling of Subassembly 8 is exposed graphically, before and after restructuring the model for manufacturing.

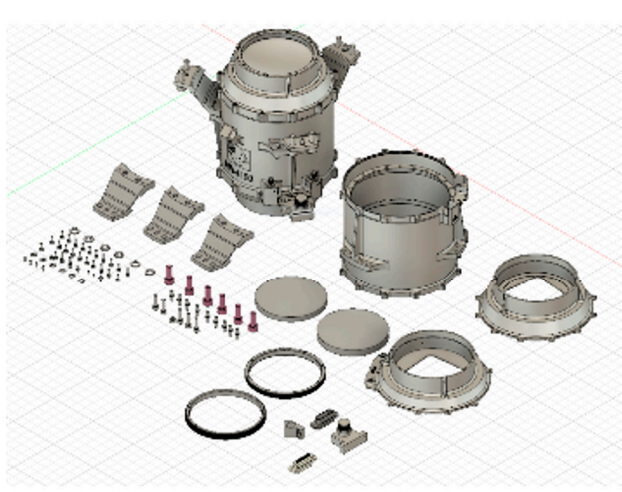

(a)

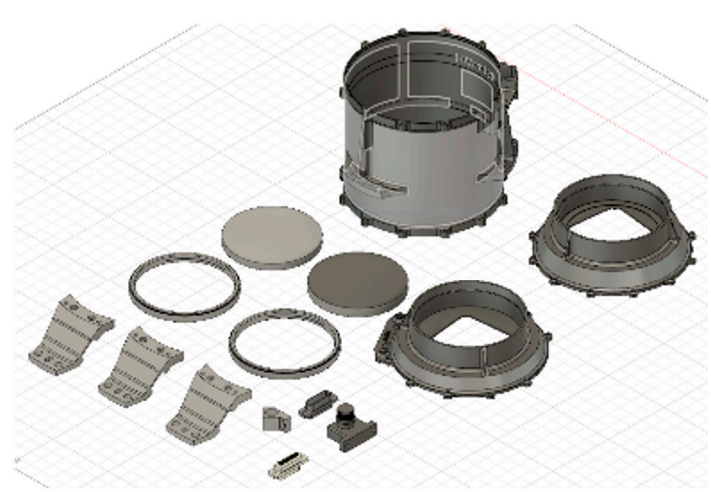

(b)

Figure 5. (a) Original subassembly 8 (82 pieces). (b) Subassembly 8 prepared for manufacturing (14 pieces). 


\subsubsection{Adaptation of the Models to the Means of Manufacturing}

The dimensions of the subassemblies are sometimes larger than the volume of the 3D printers. Therefore, it is necessary to divide the elements so that they adapt to our possibilities. In the upper left part of Figure 6, one of the parts into which the piece has been divided is located above the 3D printer work area.

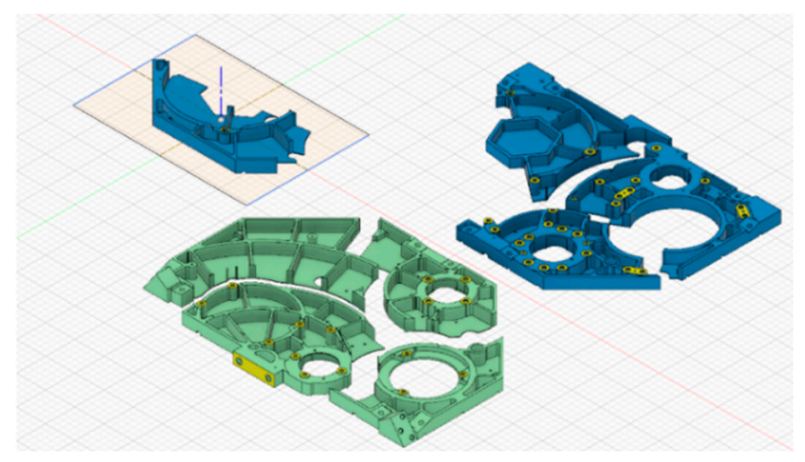

Figure 6. Piece divisions to fit in the 3D printer work area.

In addition, the material used in the engineering project is not the same used in the manufacture of the scale model. The geometry of the project is conditioned to its resistance in a specific material, so the change of material to print the pieces may require that geometric adaptations are generated. Some examples that need adaptations can be very thin fins or very long pieces. In both cases, it is necessary to add nerves or small tabs so that the pieces do not break when manufactured. Figure 7 shows an element that required the generation of internal reinforcements to increase its rigidity.

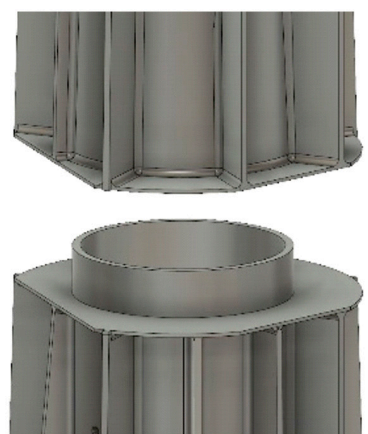

(a)

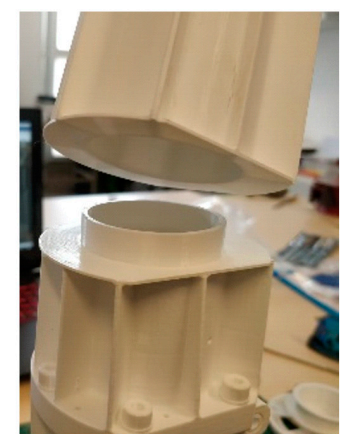

(b)

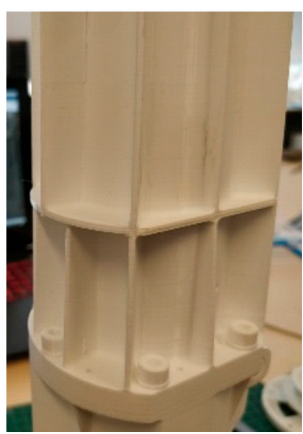

(c)

Figure 7. (a) View of the reinforcement connection between the two parts in which the piece has been divided. (b) Piece printed in two parts. (c) View of assembled printed pieces.

These geometry addition techniques may also be necessary with a shuttering function during 3D printing of the element to avoid buckling problems during printing, and which must then be removed from the final element.

\subsubsection{Pre-Allocation of the Digital Models to the Manufacturing Means}

Once the number of pieces to be printed has been reduced, it is necessary to assign which parts are printed with each 3D printer, depending on the need for resolution, or with the cutting machines, if they have laminar geometry. In order to reproduce very small pieces on a natural scale, photosensitive resin printing was used. This system has manufactured, among others, the connector of Subassembly 8 (one of the 14 pieces) due to the diameters of the pins. This analysis is performed for every part of each assembly. In Figure 8 a the connector of the Subassembly 8 is exposed in context to the rest of the elements that form it and in Figure $8 \mathrm{~b}$ a detail view of the connector. 


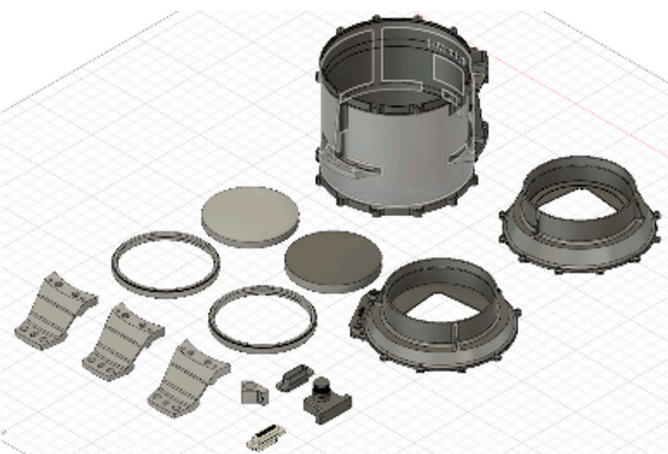

(a)

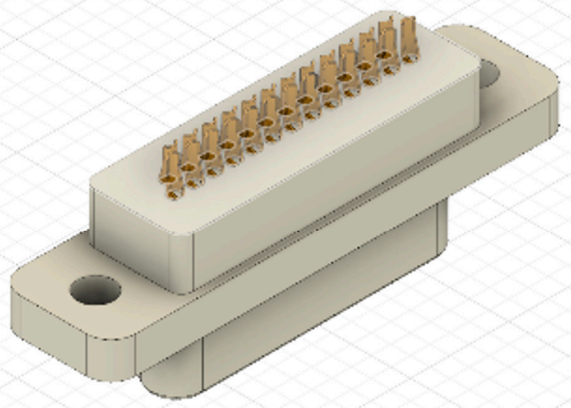

(b)

Figure 8. (a) Connector of Subassembly 8 in relation to the rest of its pieces. (b) Detail view of the connector.

In Figure 9a the printed connectors of the Subassembly 8 are exposed and in Figure $9 \mathrm{~b}$ they are presented in relation to another piece of the same subassembly, where their dimensions can be compared with those of a hand. The pins of these connectors have diameters of $0.8 \mathrm{~mm}$ and thickness of $0.1 \mathrm{~mm}$.

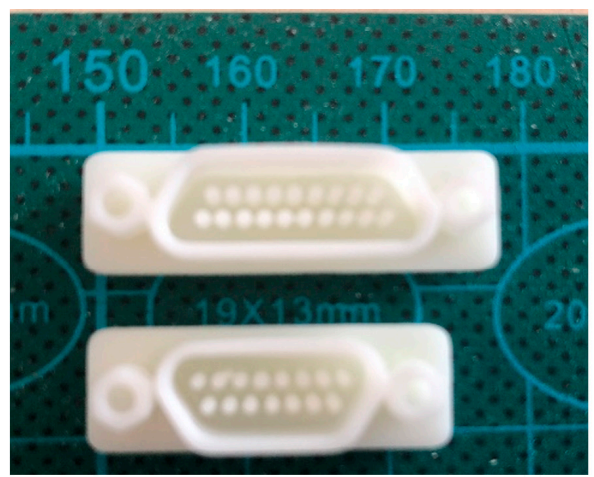

(a)

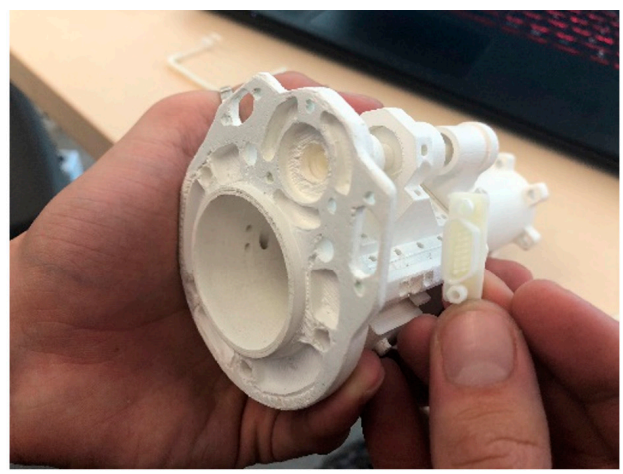

(b)

Figure 9. (a) Subassembly 8 connectors. (b) Connector and printed piece of Subassembly 8.

In SO/PHI, laminar pieces have been made by $\mathrm{CNC}$ milling and laser cutting. The support base of all the instrumentation is made in CNC milling, while the steel mirrors of the instrument and the methacrylate showcase are manufactured with a laser cutting machine. Figure 10 shows its large dimensions and its flat morphology, characteristics that respond to the methods of traditional model making in architecture. The reinforcing bars of the structure are manufactured by means of aluminum rods to which the printed ends in 3D have been added.

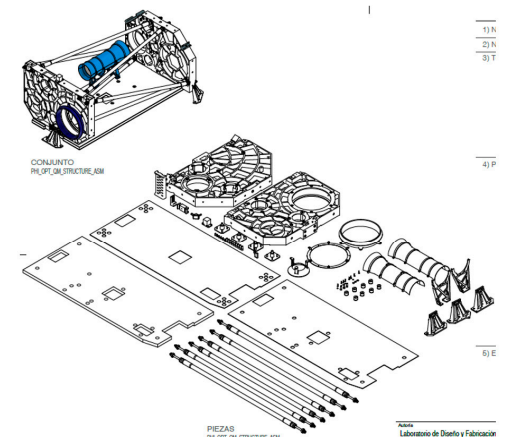

(a)

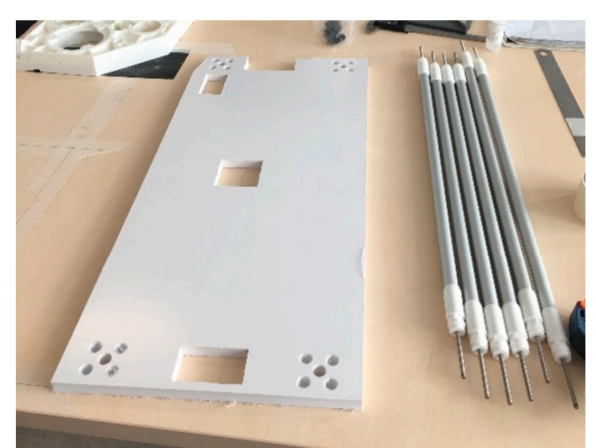

(b)

Figure 10. (a) Plane of the instrument base. (b) Base of the instrument and reinforcement rods. 


\subsubsection{Manufacturing and Finishing}

Once the geometric modifications and the adjudication of the digital manufacturing machines have been made, it is necessary to make modifications in the printed elements in order to generate a uniform HDM in terms of texture and color. Figure 11a shows an example of joining pieces that had been printed in several parts, and in Figure $11 \mathrm{~b}$ the process of painting to match the color.

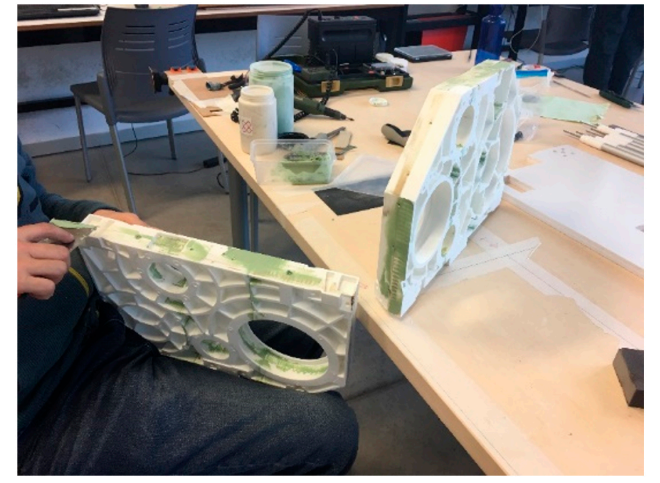

(a)

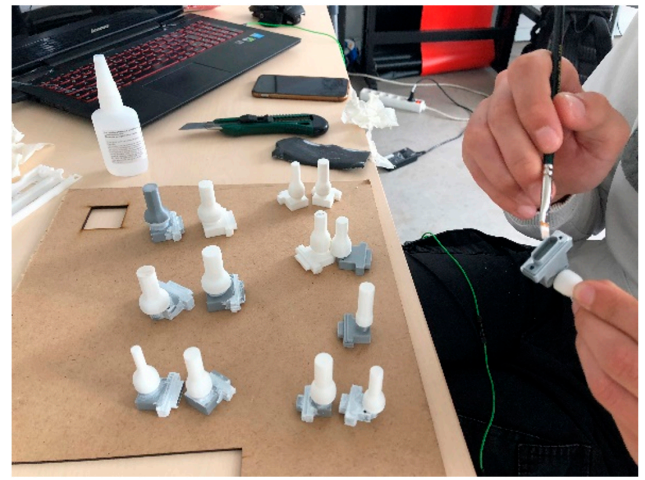

(b)

Figure 11. (a) Process of joining two elements. (b) Process of matching color.

Finally, for its exhibition, a methacrylate urn is designed and manufactured, as well as a package to allow displacements without damaging the scale model. In this case, both elements have been made with cutting machines. In the case of the urn with laser cutting and in the packaging with CNC milling. Figure 12 shows the SO/PHI, from its digital model to its final manufacture stage as a HDM.

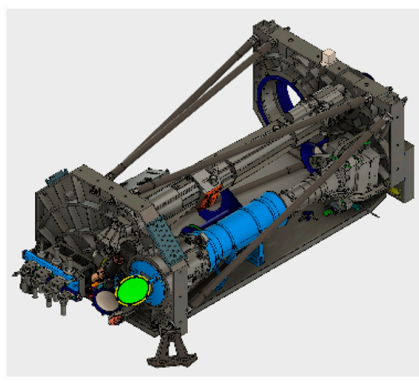

(a)

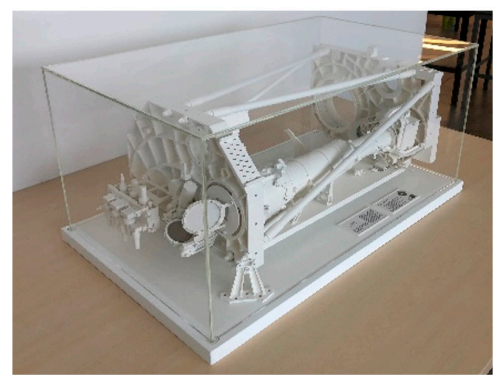

(b)

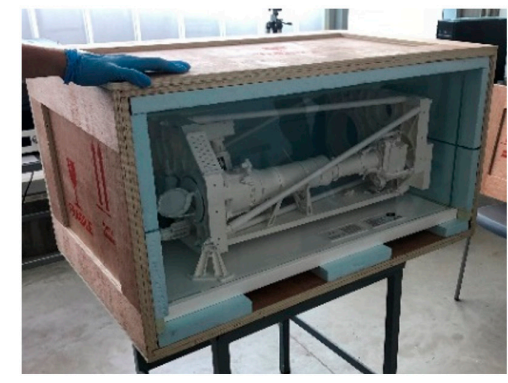

(c)

Figure 12. (a) SO/PHI digital model. (b) Final result of SO/PHI HDM. (c) HDM in its packaging.

\section{Discussion and Conclusions}

The case study consisted in the manufacture of a full-scale high-detail model (HDM) for its conservation as part of the aerospace heritage, through the low-cost digital manufacturing of the PHI instrument for the Solar Orbiter mission. This project was carried out under a collaborative approach, low cost manufacturing, and graphic engineering planning. For the collaboration of different teams and their supervision, techniques of organization and distribution of subassemblies were applied. This organization was essential to know at all times of the project what was the location of each element and its state of manufacture.

Aerospace engineering entails complexity that cannot be transmitted simply through texts, photographs, or simplified scale models. Although, these modalities serve for the conceptual preservation and the diffusion in educative environments of this heritage of engineering, the development of models of HDMs are necessary for the scientific and professional panorama. For this reason, it is proposed to add these scale models to the current categories [22]. 
Other authors have promoted digital graphic representation techniques such as augmented reality for the conservation of industrial heritage [15] or the application of BIM techniques for the representation of architectural heritage with a high level of detail [16], but the materialization of the work in a physical element can test and evaluate it [19]. This research generates a proposal that combines the level of detail in CAD modeling and benefits of its materialization.

This complexity has also been reflected in the need to solve problems through collaborative work and planning, with the particularity of working with geometric modeling in 3D. In this sense, results are presented that agree with Vila, Ugarte, Ríos, and Abellán [25], Fusion 360 has worked and allowed team work both synchronous and asynchronous, so that supervision tasks could be done through Fusion 360. In addition, printing times were optimized, as there were no downtimes between the low-cost digital manufacturing of highly complex engineering projects is possible, but far from being an instantaneous process. This experience fosters the generation of seven stages of graphic engineering and planning for the elaboration of models of high level of detail from the reception of a 3D digital model: identification and organization of subassemblies, analysis of the digital files, digital model repair, digital model restructuration to optimize their manufacture, adaptation of the models to the means of manufacturing, pre-allocation of the digital models to the manufacturing, and manufacturing and finishing.

The importance of HDM is supported by its role as a source of information in historical investigations [21]. However, the models have usually led to geometric simplifications due to the cost involved in representing the engineering project in detail $[20,22]$. This research contributes to the achievement of this high-detail model by the combination of two 3D printing types: fused deposition modeling and digital light processing (DLP). DLP have allowed to manufacture elements in photosensitive resin with very small dimensions at full-scale, being reproduced in the environment of the engineering project. This means a step forward in the detailed representation of engineering projects as opposed to architectural scale models that require geometric simplifications because they cannot be uniformly scaled [3].

This research has developed a full-scale high-detail model of the SO/PHI instrument for the Solar Orbiter mission of the European Space Agency through low-cost digital fabrication techniques and collaborative work. The HDM is presented as a tool that contains complex information that seems especially suitable for the aerospace sector, in which most of the designs are launched into space and there is no record beyond the digital model, texts, and photographs. In addition, seven engineering graphics procedures for the manufacture of HDMs have been provided to enable other professionals and scientists to contribute to the transfer and conservation of industrial heritage.

Author Contributions: Conceptualization, J.L.S. and V.L.C.; Methodology, software investigation and resources, J.d.I.T.-C. and M.D.D.-A.; Formal analysis and the writing of the manuscript, J.L.S. and V.L.C.; Supervision, project administration, and funding acquisition, M.D.D.-A. and J.d.1.T.-C.

Funding: This research was partially funded by Ministerio de Ciencia e Innovación, grant number HAR2017-85169-R: Fundición artística de micro esculturas diseñadas por ordenador, mediante el desarrollo de técnicas de impresión 3D basadas en el procesado digital de luz". It has also been funded by National Institute of Aerospace Technology (INTA) and Andalusian Astrophysics Institute (IAA) through the project "Réplicas Dummies a escala 1:1 del instrumento espacial PHI para la misión Solar Orbiter de la ESA".

Conflicts of Interest: The authors declare no conflict of interest.

\section{References}

1. Instituto de Astrofísica de Andalucia: Unidad de Desarrollo de Instrumental y Tecnológico SOPHI. Available online: https://udit.iaa.csic.es/en/content/sophi (accessed on 24 May 2019).

2. Campbell, R.I.; Bourell, D.; Gibson, I. Additive manufacturing: Rapid prototyping comes of age. Rapid Prototyp. J. 2012, 18, 255-258. [CrossRef]

3. Stitic, A.; Robeller, C.; Weinand, Y. Experimental investigation of the influence of integral mechanical attachments on structural behaviour of timber folded surface structures. Thin-Walled Struct. 2018, 122, 314-328. [CrossRef] 
4. Dimitrov, D.; Schreve, K.; de Beer, N. Advances in three-dimensional printing-state of the art and future perspectives. Rapid Prototyp. J. 2006, 12, 136-147. [CrossRef]

5. Lowke, D.; Dini, E.; Perrot, A.; Weger, D.; Gehlen, C.; Dillenburger, B. Particle-bed 3D printing in concrete construction-Possibilities and challenges. Cem. Concr. Res. Pergamon 2018, 112, 50-65. [CrossRef]

6. Stitic, A.; nguyen, A.; Rezaei Rad, A.; Weinand, Y. Numerical Simulation of the Semi-Rigid Behaviour of Integrally Attached Timber Folded Surface Structures. Build. Multidiscip. Digit. Publ. Inst. 2019, 9, 55. [CrossRef]

7. Oropallo, W.; Piegl, L.A. Ten challenges in 3D printing. Eng. Comput. 2016, 32, 135-148. [CrossRef]

8. Rojas-Sola, J.; Galan-Moral, B.; la Morena-De la Fuente, D. Agustín de Betancourt's Double-Acting Steam Engine: Geometric Modeling and Virtual Reconstruction. Symmetry 2018, 10, 351. [CrossRef]

9. Meier, C.; Saorín, J.L.; de la Torre-Cantero, J.; Díaz-Alemán, M.D. Alternative divulgation of the local sculptural heritage: Construction of paper toys and use of the minecraft video game. Sustainability 2018, 10, 4262. [CrossRef]

10. Saorín, J.L.; de la Torre-Cantero, J.; Meier, C.; Melián-Díaz, D.; Ruiz Castilló, C.; Bonnet de León, A. Creación, visualización e impresión 3D de colecciones online de modelos educativos tridimensionales con tecnologías de bajo coste. Caso práctico del patrimonio fósil marino de Canarias. Educ. Knowl. Soc. 2016, 17, 89-108. [CrossRef]

11. Acierno, M.; Cursi, S.; Simeone, D.; Fiorani, D. Architectural heritage knowledge modelling: An ontology-based framework for conservation process. J. Cult. Herit. 2017, 24, 124-133. [CrossRef]

12. Walsh, J.S.P. Protection of humanity's cultural and historic heritage in space. Space Policy 2012, $28,234-243$. [CrossRef]

13. Gorman, A. Culture on the Moon: Bodies in time and space. Archaeol. J. World Archaeol. Congr. 2016, 12, 110-128. [CrossRef]

14. Remondino, F. Heritage recording and 3D modeling with photogrammetry and 3D scanning. Remote Sens. 2011, 3, 1104-1138. [CrossRef]

15. Rojas-Sola, J.I.; Aguilera-García, Á. Virtual and augmented reality: Applications for the learning of technical historical heritage. Comput. Appl. Eng. Educ. 2018, 26, 1725-1733. [CrossRef]

16. Brusaporci, S. The Representation of Architectural Heritage in the Digital Age. In Encyclopedia of Information Science and Technology, 3nd ed.; Yoder, J., Henning, C., Eds.; IGI Global: Hershey, PA, USA, 2015; pp. 4195-4205.

17. De la Torre-Cantero, J.; Saorín, J.L.; Meier, C.; Melián-Díaz, D.; Drago-Díaz Alemán, M. Creación de réplicas de patrimonio escultórico mediante reconstrucción 3D e impresoras 3D de bajo coste para uso en entornos educativos. Arte Individuo Y Soc. 2015, 27, 427-444. [CrossRef]

18. NASA 3D Resources. Available online: https://nasa3d.arc.nasa.gov/models (accessed on 2 March 2019).

19. Hallgrimsson, B. Prototyping and Model Making for Product Design; Laurence King Publishing: London, UK, 2012.

20. Yongnian, Y.; Li, S.; Zhang, R.; Lin, F.; Wu, R.; Lu, Q.; Xiong, Z.; Wang, X. Rapid prototyping and manufacturing technology: Principle, representative technics, applications, and development trends. Tsinghua Sci. Technol. 2009, 14, 1-12.

21. Granado Castro, G.; Barrera Vera, J.A.; Aguilar Camacho, J. La maqueta de Cádiz de 1779. Utilidad militar o metáfora de poder. Proy. Prog. Arquit. 2016, 15, 16-29.

22. Salwa, S. Classifying Physical Models and Prototypes in the Design Process: A study on the Economical and Usability Impact of Adopting Models and Prototypes in the Design Process. In Proceedings of the DESIGN 2014 13th International Design Conference, Dubrovnik, Croatia, 19-22 May 2014; Marjanović, D., Štorga, M., Pavković, N., Bojčetić, N., Eds.; Faculty of Mechanical Engineering and Naval Architecture and The Design Society: Zagreb, Croatia, 2014; pp. 1-10.

23. Al-Samarraie, H.; Saeed, N. A systematic review of cloud computing tools for collaborative learning: Opportunities and challenges to the blended-learning environment. Comput. Educ. 2018, 124, 77-91. [CrossRef]

24. Autodesk Fusion 360: Fusion 360 for Hobbyist and Makers. Available online: https://www.autodesk.com/ campaigns/fusion-360-for-hobbyists (accessed on 25 May 2019).

25. Vila, C.; Ugarte, D.; Ríos, J.; Abellán, J.V. Project-based collaborative engineering learning to develop Industry 4.0 skills within a PLM framework. Procedia Manuf. 2017, 13, 1269-1276. [CrossRef]

(C) 2019 by the authors. Licensee MDPI, Basel, Switzerland. This article is an open access article distributed under the terms and conditions of the Creative Commons Attribution (CC BY) license (http://creativecommons.org/licenses/by/4.0/). 